\title{
The Adaptive Capabilities of Chinese Students Studying In Chinese, British and Russian Universities
}

\author{
Nina V. Bordovskaia ${ }^{1}$, Charles Anderson ${ }^{2}$, Natalia Bochkina ${ }^{3}$ \& Elena I. Petanova ${ }^{1}$ \\ ${ }^{1}$ Saint-Petersburg State University, St. Petersburg, Russia \\ ${ }^{2}$ School of Education, The University of Edinburgh, UK \\ ${ }^{3}$ The University of Edinburgh and Maxwell Institute, Edinburgh, UK \\ Correspondence: Professor Nina V. Bordovskaia, Saint-Petersburg State University, St. Petersburg, Russia.
}

Received: April 29, 2018

Accepted: June 28, 2018

Online Published: July 4, 2018

doi:10.5430/ijhe.v7n4p1

URL: https://doi.org/10.5430/ijhe.v7n4p1

\begin{abstract}
This article presents a comparative study of the personal adaptive capabilities of Chinese students studying in Chinese, British and Russian universities. The study involved 224 Chinese first-year students who formed 3 groups: Group 1, 96 first-year students studying in China; Group 2, 100 Chinese first-year students studying in Russia; Group 3, 28 Chinese first-year students studying in the UK. The instruments employed were: a Personality questionnaire (adapted Rogers-Dymond method), the Big Five and the Method of studying the Research Potential of students (Bordovskaia et al., 2017). The study found that for all Chinese students, the general predictors of adaptation to university education are "openness" and "agreeableness". The differences are that the personal resources for the adaptation of Chinese students in Chinese and Russian universities are "research potential", in the British university "neuroticism", "extraversion" and "conscientiousness (self-control)". The findings point up the conditions for ensuring the future academic, social and communicative success of Chinese students in the educational environments of British, Russian and Chinese universities, and allow one to predict the reasons for the difficulties faced by individual students.
\end{abstract}

Keywords: Chinese students, international students, adaptation, adaptation barriers, personal resource, research potential

\section{Introduction}

\subsection{Adaptation of International Students}

In the last decade, in the context of intensified processes of migration, the development of international contacts in the field of education and the rapid change in the requirements for professional activity, there has been a growing interest in researching the challenges young people face in adapting to new living conditions, education and work. In particular, there has been an increasing interest in studying the question of the adaptation of international students to the new learning conditions, and life in the culture and socio-political climate, of another country.

Since the beginning of the 21 st century, with a significant growth in the economy and the expansion of China's international relations with the most developed countries in the world, the number of Chinese students studying in the universities of these countries, particularly in British and Russian universities, has been increasing every year. As a result, both students and university teachers of host universities have faced new challenges of psychological, socio-cultural and pedagogical adjustment. These challenges have engaged the attention of psychological and pedagogical researchers in recent years, and are the subject of this current article.

\subsection{Challenges Faced by International Students: Literature Review}

Foreign students, regardless of their country of origin, may face a number of interrelated problems when they move to a Russian or British university. What are the problems and are they specific to Chinese students studying in foreign universities, for example, in Britain and Russia?

To begin with, Chinese education has been viewed as deeply imbued with traditional Confucian values and norms of interaction. Chinese students are characterized as belonging to the Confucian Heritage Culture (CHC). The main features attributed to $\mathrm{CHC}$ include: the emphasis on education as a means of conveying the cultural tradition; a hierarchical relationship between teachers and students; and a collectivist orientation 'with the stress upon managing 
relationships in a harmonious manner'(Currie, 2007, p.541). These values and norms of interaction can be viewed as contradicting modern Western expectations of university students, where the emphasis is on autonomy in learning, critical thinking and participation in critical discussions. Here, however, some cautionary notes have been sounded. $\mathrm{Gu}$ (2011, p.127), for example, has observed that 'a deterministic notion of culture ... fails to take into account the role of individual agency and resilience in managing setbacks and challenges in adverse circumstances. These qualities are individualized and may vary greatly even within a mono-cultural group'. This point is backed up by the study by Gu, Schweisfurth and Day (2010) which found that 'personal, pedagogical and psychological factors are as important as organisational and social cultures in influencing students' adaptation, identity change and ultimate success'(p.7).

While there is debate over the influence of Confucian Heritage Culture, it is acknowledged that Chinese students, entering a British or Russian university, may first of all face the problems of academic adaptation. Chinese students will enter a new linguistic environment and will have to use Russian or English at the high level required for university study. They may, for example, not have the level of linguistic understanding to comprehend all the scientific information in the study of their subjects (Gao, 2005). In addition, they will need to master the very specific forms of communication and writing, the academic literacies, that are required in their subject in their host country (Edwards, Ran and Li, 2007). However, studies by Biggs (Biggs and Watkins, 2001) and by other researchers such as Marton et al. (1996) and Kember (1996) point up that the emphasis on memorisation in CHC should not be viewed straightforwardly as leading to mechanical rote-learning. Rather memorisation within CHC can be very much an active process and one that is associated with the pursuit of understanding, as learners practise and review material.

These difficulties and the variability of the response of Chinese students to studying in a Western environment can be illustrated from a recent study that tracked the adaptation of Chinese students, from contrasting subject areas, over the course of their study for a Masters degree in a British university (Zhao, Sangster and Hounsell, 2017). Looking first at autonomy in learning, some of the students in this study struggled to assume greater responsibility for their learning and displayed a preference for the more teacher-led style of pedagogy they had experienced in China, while others, including the following student, had assimilated a different conception of personal responsibility:

Previously I thought learning was to learn everything taught by the teachers ... But now at the Master's level, learning is more important than teaching.

(Zhao, Sangster and Hounsell, 2017, p.194)

A similar picture emerged in relation to critical and analytical thinking where 'many of the students found it a struggle to put into day-to-day practice what was expected of them, even when they were able to acknowledge the requirement to think critically' (Zhao, Sangster and Hounsell, 2017, p.199). Students also had to adapt to the appropriate forms of listening, speaking, reading and, in particular, writing within their new university environment. On writing, Zhao and her colleagues noted that 'challenges with extended writing were reported in all three programmes, even those where statistical work was prominent' (Zhao, Sangster and Hounsell, 2017, p.196).

Comparable findings concerning the challenges of mastering academic discourse in British and Russian universities are found in a considerable number of other studies, with some, such as Edwards, Ran and Li (2007), highlighting how reading can be a taxing matter: 'In the context of western university education, reading creates fundamental problems for Chinese students, both in terms of their reliance on the teacher for guidance as to what they should be reading and in terms of the sheer volume of reading recommended by lecturers' (Edwards, Ran and Li, 2007, p.391).

Russian scholars have considered the problem of academic adaptation of Chinese students in the context of their psychological adaptation to academic higher education through the introduction of the concept of "research potential" (Bordovskaia et al., 2017) and determined the degree of the research potential of Chinese students adapting to study at the Russian university (Bordovskaia and Fan, 2016).

The second problem that may be faced by Chinese students studying in British or Russian universities is the difference in the forms and requirements of instruction, norms and methods of pedagogical interaction in a new socio-cultural environment. This is a problem of psychological adaptation of Chinese students to new learning conditions.

An incisive summary of current views of Confucian Heritage Culture is provided by Jin and Cortazzi (2006, p.12) in the following paragraph:

In the central relation between teacher and student the teacher is often regarded as an authoritative parent to whom respect and obedience are due, but this classic image of the relationship of filiality 
overlooks the reciprocity of caring, concern and cherishing which also characterises it in Chinese tradition. While the common picture is one of heavy memorising and disciplined reciting of texts in a transmission model of learning, this ignores the strong traditional elements of the student's own efforts, the need for reflective thinking and independent interpretation, for internalisation of understanding and putting what is learned into practice. It is the combination of these elements which characterises student learning in the Confucian heritage.

Investigating how Chinese students cope with these transitions, Russian and Chinese researchers (Danilenko, Li and $\mathrm{Xu}, 2015)$ have examined the degree of adaptability of Chinese students at various stages of education in universities in Russia and China.

The third problem for Chinese students studying in British or Russian universities is connected with overcoming what has been termed 'cultural shock' (Ward, Bochner and Furnham 2001) or 'acculturative stress' (Berry, 2005), that is with the problems of socio-cultural adaptation. The term 'culture shock' has been used by some researchers, such as Currie (2007), who have examined the problems of students' psychological adaptation, to capture the stresses created by gaps and discontinuities in experience and understanding. Pak and Wang (2008), for example, revealed the culture shock of Chinese students studying in Russian universities, analysed its causes and consequences and proposed ways to overcome it. Berry (2005), who researches intercultural contact, argues that 'acculturative stress' is a more appropriate term than 'culture shock', as the word acculturation draws 'attention to the fact that two cultures are interacting, and producing the stress phenomena' (p.708), suggesting a dynamic interplay in the intercultural encounter. This concept of 'acculturative stress' has informed a number of recent studies of the sociocultural adaptation of Chinese students studying abroad, (for example, Brown and Holloway, 2008; Gu and Schweisfurth, 2006: Tian and Lowe, 2012).

There is increasing interest among researchers from different countries in investigating the problem of socio-cultural adaptation of Chinese students. For example, a study looking at Chinese students' general social integration into the university community (Spencer-Oatey et al., 2017) found that many Chinese students were dissatisfied with their range of friendships and experienced challenges in socialising with students of other nationalities.To confirm this position, Liu and Petanova (2016) have identified cognitive-behavioral predictors of socio-psychological adaptation of Chinese students studying at home, and investigated the adaptability of Chinese students compared with Russian students.

\subsection{Aims}

Summarizing the analysis of the work of researchers on the problems faced by Chinese students studying in foreign universities, we note that they, as a rule, consider the three problems we identified above either separately or as a pair (psychological and academic adaptation, social and psychological adaptation). In our study we consider all three problems simultaneously in order to address the following question: what variables of personality can affect the sociocultural adaptation of Chinese students in Russian and British universities, as compared to those studying in home universities. That is, from our point of view, it is important in current studies of the question of the adaptation of foreign students to take into account a set of potential influences. This applies in particular to the adaptation of Chinese students studying in Russian and British universities where one needs to avoid presenting a homogeneous picture of the "Chinese student" and undervaluing the role of psychological factors.

The study reported here has been guided by these considerations and has pursued the purpose of identifying the psychological factors that may contribute to the better adaptation of Chinese students to the educational environments of Russian and British universities.

\section{Methodology}

\subsection{The Concept of the Study}

In studying the conditions that affect the level of adaptation of Chinese students to Russian and British universities we were guided by the following theoretical considerations.

The academic-social-psychological adaptation of students to the conditions of the educational environment of a university is the leading component in the structure of their adaptation to higher education (Bezyulyova, 2008). Therefore, the adaptation of foreign first-year students to the conditions of study at a university is understood as a socio-psychological adaptation to the conditions of its educational environment:

- to its forms (direct instruction and guidance / cooperation),

- its styles of interaction (authoritarian / democratic), 
- its ethical rules and attitudes (tolerant / intolerant) on the part of teachers and administration regarding behavior in the classroom and in the wider educational environment of the university.

Kong (1991) has delineated active and passive forms of socio-psychological adaptation and in this study we set out to establish the degree to which Chinese students exhibited the personal resource of active adaptation. According to Chinese scholars (Xu, Yu, and Li, 2005; Liang, 2004) active adaptation combines the favorable factors of the learning environment and the positive resources of the individual. When there is active adaptation, that is, when there is a high level of adaptability to the conditions of the university educational environment (as determined by the method of Rogers and Dymond, 1954), there is a greater likelihood of individuals realizing their potential, which should be reflected in their academic achievement.

The study of the dependence of the degree of adaptation of a foreign student on their personal characteristics rests on the foundations of the dispositional personality theory of Allport (1955). In accordance with this theory, the basic characteristics of the personality play a decisive role in the adoption of socially adaptive behavior.

Research activity has always been and remains the most important component of productive higher education, and is central to the development of the student. It stimulates the student's need to find new knowledge and discover the unknown. Therefore, it is of central importance to investigate the student's research potential, given that it is the basis for their academic adaptation. The lack of sufficient research potential can hamper a student's adaptation process to the new learning environment of a university and the achievement of good educational results. (Fan, Petanova, 2017; Kostromina et al., 2014; Bordovskaia, 2013)

\subsection{Research Questions and Research Tasks}

To take ahead its central purposes, the study adopted the following two research questions:

1. What are the psychological factors that may contribute to the better adaptation of Chinese students to the educational environments of Russian and British universities?

2. What similarities and differences are there in the predictors of the socio-psychological adaptability of Chinese students studying in universities in China, Russia and Britain?

These research questions were addressed in the following research tasks:

1. To determine and compare the degree of active socio-psychological adaptability of Chinese students to the new educational environment of a home, Russian or British university, with comparisons made across these three sites.

2. To determine and compare the level of the research potential of these same students.

3. To determine and compare the personality traits of these same students.

4. To study the relationships between socio-psychological adaptation, research potential and personality traits.

5. To determine and compare the psychological predictors of adaptability of the Chinese students among their personal traits, at each of the three sites.

\subsection{Methods}

Now we describe the methods to address the research tasks described in Section 2.2.

1. To study Chinese first-year students' degree of potential to adapt actively to a new environment, Rogers and Dymond's (1954) questionnaire that measures socio-psychological adaptation was used. It contains 101 statements with a 7 point score from 0 to 6 and has 13 scales. The first scale in this instrument, "adaptation - disadaptation", is the most important one for our study. The sum of scores on this scale allowed us to gauge the degree of adaptability of the three groups of Chinese students. The total scores on the other 12 scales (self-acceptance - self-rejection, acceptance of others - rejection of others, emotional comfort - emotional discomfort, external control - internal control, dominance - dependence, and escapism) represented the degree of expression of these personality traits associated with their adaptability. After analysing the data for each group, a comparison was made between the degree of active adaptivity and the associated indicators of these 12 personality traits in Chinese students in the following sequence:

- studying at home and in the Russian university,

- studying at home and in the British university,

- students at the Russian university and the British university. 
(Petanova, Bordovskaia, Fan, Wang, 2017; Liu, Petanova, 2016; Shamionov, Grigoryeva, Grigoryev, 2014; Jimenez, Lopez-Zafra, 2011)

2. In addition to the data obtained by this first method, we employed the Big Five methodology to allow us to clarify whether the Chinese students in these three groups differed in basic characteristics of personality that might impact on their adaption to a new environment, such as: extraversion, agreeableness, conscientiousness, neuroticism (the opposite pole is emotional stability), openness. The test consists of 75 paired, opposite in value, stimulus statements characterizing human behavior, with a 5-point score $(-2,-1,0,1,2)$. Summation of these scores established the level of the relevant personality characteristics of each participant in the study.

3. The methods of studying students' research potential developed by Bordovskaia et al. (2017), (translated into English by the authors of this paper), allowed us to identify and compare the overall level of academic adaptability of all three groups of Chinese students, i.e. their readiness to engage with the educational and research activities they will meet at university.

Students' research potential (RP) is considered as an integral element of their personal resources, both internal and acquired in the process of education, upbringing and personal development; namely, the strength of intellect and maturity, cognitive, motivational and organizational personal attributes that are required to master educational and research activities. According to our model, three components of RP are distinguished: motivational (psychological resource of high propensity), cognitive (self-regulating cognitive system that ensures the success of solving educational and research problems) and behavioral (personality qualities that ensure self-organization of activity and self-regulation of behavior in an educational environment).

When choosing this method, we were guided by the following considerations.

Consideration 1. Given that adaptability in a new situation is one of the characteristics of research behavior (Bordovskaia et al., 2017), and the basic characteristic of Research Potential is the student researcher's human need, (for new information, impressions and knowledge, and results of activity), then to study the academic adaptability of Chinese students we chose a methodology developed by the team under the leadership of N.V. Bordovskaia. The research potential of the student in this study is viewed as the opportunities achieved as a result of their previous education and development that can be actualized under the influence of certain conditions and ensure the achievement of personally significant and socially valuable achievements in the field of education in a new environment: in a university in China, or abroad in Great Britain or Russia.

Consideration 2. University study involves the adoption of approaches to studying that make specific cognitive, motivational and behavioural demands on students and the method of investigating RP developed by Bordovskaia aims to capture the degree to which an individual student understands and is following these demands. It has been used in quite a number of recent psychological and pedagogical studies, the results of which have been presented at international scientific conferences in London (2012), Madrid (2013), Istanbul (2014), Barcelona (2016), St. Petersburg (2011-2017); and tested for reliability and validity.

The internal consistency of the scales by the Cronbach coefficient $\alpha$ was $\alpha$ total $=0.899$ for the total scale, which corresponds to the permissible value; the $\alpha$ Cronbach for the motivational component was $\alpha$ motivac $=0.735$, for the cognitive component $\alpha$ cognitive $=0.791$, for the behavioral component $\alpha=0.787$. An additional test for reliability was carried out through evaluation of its test-retest reliability. The evaluation was carried out twice with an interval of one month among the students of the St. Petersburg State University's medical and philosophical faculty. The analysis was carried out using Spearman's rank correlation test. Significant correlations were obtained both for the total indicator level of the Research Potential $(\mathrm{r}=0.435, \mathrm{p}=0.002)$ and for all of its components: motivational $(\mathrm{r}=$ 0.585; $\mathrm{p}<0.0001)$; cognitive $(\mathrm{r}=0.346 ; \mathrm{p}=0.012)$; behavioral $(\mathrm{r}=0.475, \mathrm{p}=0.001)$. Thus, it can be concluded that the degree of reliability of the RP instrument, which reflects the accuracy and stability of its results, corresponds to psychodiagnostic requirements.

The questionnaire contains 51 items with a 10-point response scale, the questions of which are combined into 3 sub-scales: the motivational, cognitive and behavioral structural components of research capacity. The overall level of research capacity is determined through the total score. High scores on the general scale and subscales indicate that the student has a sufficiently developed research potential.

4. The correlation analysis between the adaptability and personality traits of Chinese students studying at Chinese, British and Russian universities.

5. Using the method of multiple step-by-step regression analysis, the dependence of the degree of adaptation of Chinese students to study in the new educational environment of each institution on the level of their research 
potential and of their personality characteristics was studied. The dependent variable was socio-psychological adaptation, and the independent variables were: the 12 qualitative characteristics of socio-psychological adaptation within the Rogers and Dymond questionnaire; the 5 personality factors (Big Five); and the level of research potential (the methodology of Bordovskaia et al., 2017). Finally, the results of the regression analysis for pairs of three groups were compared: for students studying in China and Britain, in China and Russia, in Britain and Russia.

\subsection{Participants in the Study}

The study involved 224 Chinese first-year students who formed 3 groups: Group 1: 96 first-year bachelor level students studying in a Chinese university; Group 2: 100 Chinese first-year bachelor level students studying in a Russian university; Group 3: 28 Chinese first-year master students studying in a British university. All respondents took part in the study voluntarily, the anonymity of individual students was assured and the research was conducted following standard ethical guidelines.

\section{Results}

\subsection{Results of the First Research Task: Socio-Psychological Adaptation of Chinese Students Studying at Home and Abroad}

\subsubsection{A Study of the Level of Socio-Psychological Adaptation}

To take ahead the plan for a comprehensive comparative study of the adaptability of Chinese first-year students studying at home and abroad, we determined the percentage (of the total number of respondents) who scored at a high, medium and low level of socio-psychological adaptation. To determine the level of adaptability, we used the normative values of indicators as proposed by the authors of the methodology of "socio-psychological adaptation" (SPA) (Rogers and Dymond, 1954).

Firstly, we consider the percentages of respondents with low, medium, and high levels of adaptation, within the three groups of Chinese students: those studying at home, and those studying abroad at the Russian and British universities, allowing one to see commonalities as well as differences across the three groups.

Looking first at commonalities, across the three sites almost identical proportions of students scored within the medium level of adaptability (around 73-75\%); the overwhelming majority of Chinese students scored within the medium and high levels of the adaptability scale: in the Chinese university, 95\%, in the Russian university $92 \%$, and in the British university $100 \%$ of respondents.

Looking at the distribution of scores on other elements of the SPA we observe that $96 \%$ of Chinese students at the British university scored within the medium and high categories for "accepting themselves" and $89 \%$ within these categories for "accepting others".

In the three groups of Chinese students, the percentage of respondents with average and high rates of emotional comfort is approximately the same, around $80 \%$.

$77.8 \%$ of Chinese respondents studying at the British university, $69.8 \%$ of those studying at home, and $57 \%$ of Chinese respondents studying at the Russian university are focused on being "dominant" in their environment, which should aid them to pursue their ambitions, and only a very low number scored highly on "escapism".

There turned out to be fewer differences in adaptation of Chinese undergraduates in different socio-educational conditions than one might expect. Focusing in on differences, approximately $90 \%$ of Chinese students studying at home and at the Russian university showed a high level of "internal control" (the need for self-regulation), while 67\% of respondents in the British university, on the contrary, showed low internal control. "Emotional discomfort" is also less characteristic as an experience for Chinese students from the British university.

A very important factor that may hamper the processes of active adaptation to a new educational environment is "dependence". The percentage of "dependent" Chinese students, (i.e. those who are under the influence of others, such as teachers), among respondents in their homeland is more than among Chinese students studying in foreign universities: approximately $91 \%$ of students studying at home, $80 \%$ in Russia and $67 \%$ in Britain. Most likely, this reflects the specifics of educational processes in universities in China, Russia and Britain. A possible partial explanation of these differences is also the different level of study in the British university (Masters level) as compared to the Russian and Chinese universities (Bachelor level). 
3.1.2 Comparison of indicators of Socio-Psychological Adaptation (SPA) of Chinese Students, Adapting to University at Home and Abroad

Table 1 summarizes the pattern of results for the specific indicators of socio-psychological adaptation for the Chinese students who were studying at home and at the two universities abroad. The following paragraphs examine this pattern of results, noting statistically significant differences between groups, (as revealed by the Mann-Whitney test).

It was found that the "adaptability" of Chinese first-year students studying at home is significantly higher than that of those who are enrolled in the Russian university $(\mathrm{p}<0.035)$. A similar difference is found in elements of the SPA such as "self-acceptance " ( $p<0.012)$ and "dependence" ( $p<0.020)$. The rates of Chinese students studying in the Chinese university and the British university differ in the factors: "non-acceptance of themselves" $(p<0.001)$ and "dependence" ( $\mathrm{p}$ <.000): the ratings of students in China on these items are higher than for those studying in Britain.

Comparing the indicators of the SPA of Chinese students adapting to the conditions of study at the Russian university and British university, they differed in the following elements of the SPA: "self-rejection" $(p<0.001)$ and "dependence" ( $\mathrm{p}<0.000)$ - scores on these indicators were higher among students studying at the Russian university. In addition, students studying at the British university had more pronounced "internal control" $(\mathrm{t}=-1.987, \mathrm{p}<0.049)$. Thus, taking into account negative features as well as the degree of positive self-regulation, Chinese students at the British university were displaying the potential for greater adaptation than Chinese students studying at the Russian university.

Table 1. Significant differences in indicators of SPA of Chinese students studying at universities in different countries

\begin{tabular}{|c|c|c|c|c|}
\hline Indicators of SPA & Place of study & Mean & Mean Rank & Significance level \\
\hline \multirow{2}{*}{ Adaptability } & Chinese University & 116.73 & 107.23 & \multirow{2}{*}{0.035} \\
\hline & Russian University & 108.06 & 90.12 & \\
\hline \multirow{2}{*}{ Self-acceptance } & Chinese University & 37.73 & 108.34 & \multirow{2}{*}{0.017} \\
\hline & Russian University & 33.90 & 89.06 & \\
\hline \multirow{2}{*}{ Dependence } & Chinese University & 20.54 & 107.78 & \multirow{2}{*}{0.025} \\
\hline & Russian University & 18.23 & 89.60 & \\
\hline \multirow{2}{*}{ Self- rejection } & Chinese University & 16.50 & 67.83 & \multirow{2}{*}{0.001} \\
\hline & British University & 10.70 & 41.28 & \\
\hline \multirow{2}{*}{ Dependence } & Chinese University & 20.54 & 71.03 & \multirow{2}{*}{0.000} \\
\hline & British University & 12.96 & 29.91 & \\
\hline \multirow{2}{*}{ Self- rejection } & Russian University & 16.66 & 69.76 & \multirow{2}{*}{0.001} \\
\hline & British University & 10.70 & 42.67 & \\
\hline \multirow{2}{*}{ Internal control } & Russian University & 43.80 & 60.55 & \multirow{2}{*}{0.042} \\
\hline & British University & 49.63 & 56.56 & \\
\hline \multirow{2}{*}{ Dominance } & Russian University & 8.49 & 59.64 & \multirow{2}{*}{0.010} \\
\hline & British University & 10.19 & 80.17 & \\
\hline \multirow{2}{*}{ Dependence } & Russian University & 18.23 & 70.09 & \multirow{2}{*}{0.000} \\
\hline & British University & 12.96 & 41.46 & \\
\hline
\end{tabular}

Summarizing the results obtained, it can be argued that the effectiveness of the SPA of Chinese students is not so much dependent on the social and cultural factors associated with "learning at home", but rather on the "specificity of the educational environment" in which the adaptation of Chinese international students is taking place. 


\subsection{The Results of the Second Research Task: The "Research Potential" (RP) of Chinese Students Studying at Home and Abroad}

As an earlier section of this article has indicated, we determined the research potential of Chinese students studying in the different educational settings of these three universities. In the following sub-sections we discuss significant differences identified in the data between the total indicator of the research potential (RP) and its three components (using the Mann-Whitney test).

\subsubsection{Levels of RP of Chinese Students Studying at Home and Abroad}

We identified groups of Chinese students (in percentages) who have a low, medium and high level of RP (Figure 1).

It will be seen from Figure 1 that around $40 \%$ of Chinese students across all the three universities scored within the medium level of research potential. Around one third of the students studying at the Russian and Chinese universities scored within the low level of RP, while a third of the students in the British university had scores within the high level of RP.

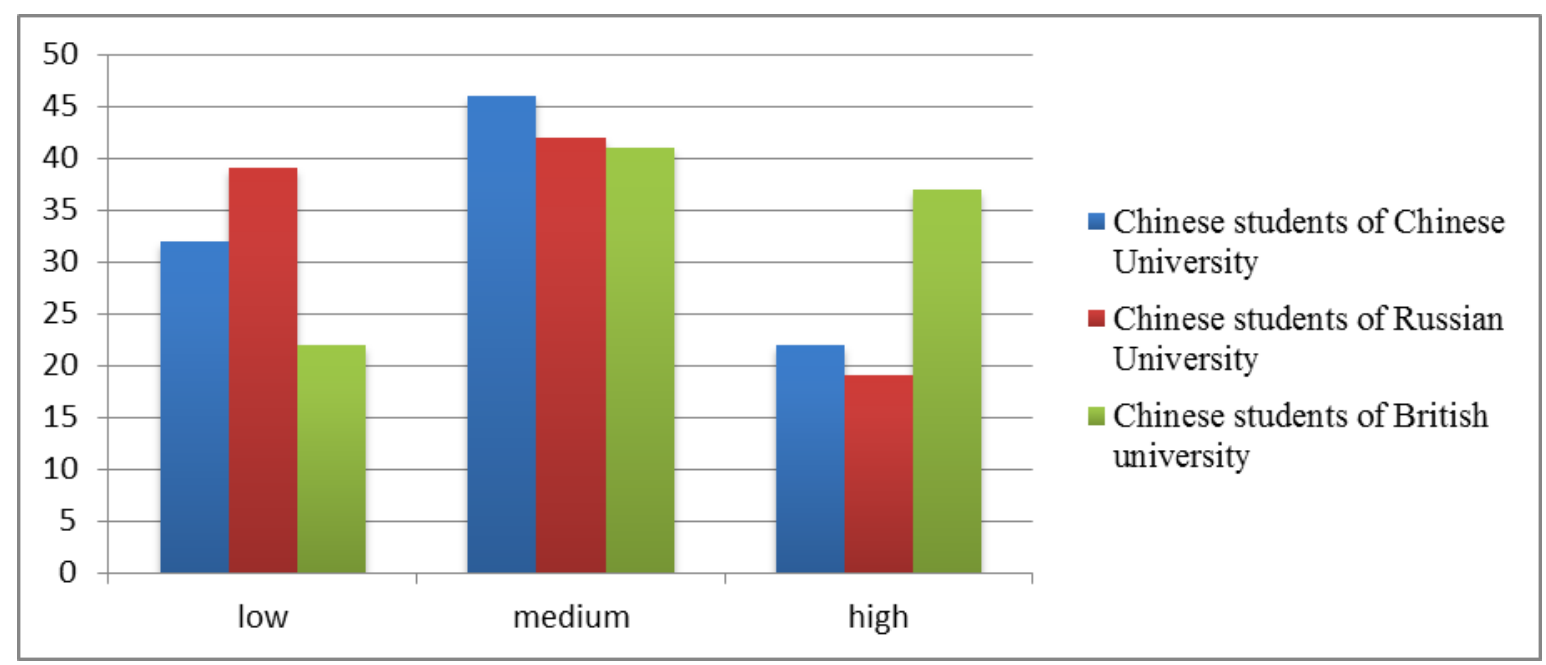

Figure 1. Percentages of Chinese students in the three universities within the three different levels of research potential.

Moving to look in turn at findings concerning each of the three structural components of research potential, Figure 2 gives a summary picture of scores on the Motivational component of RP.

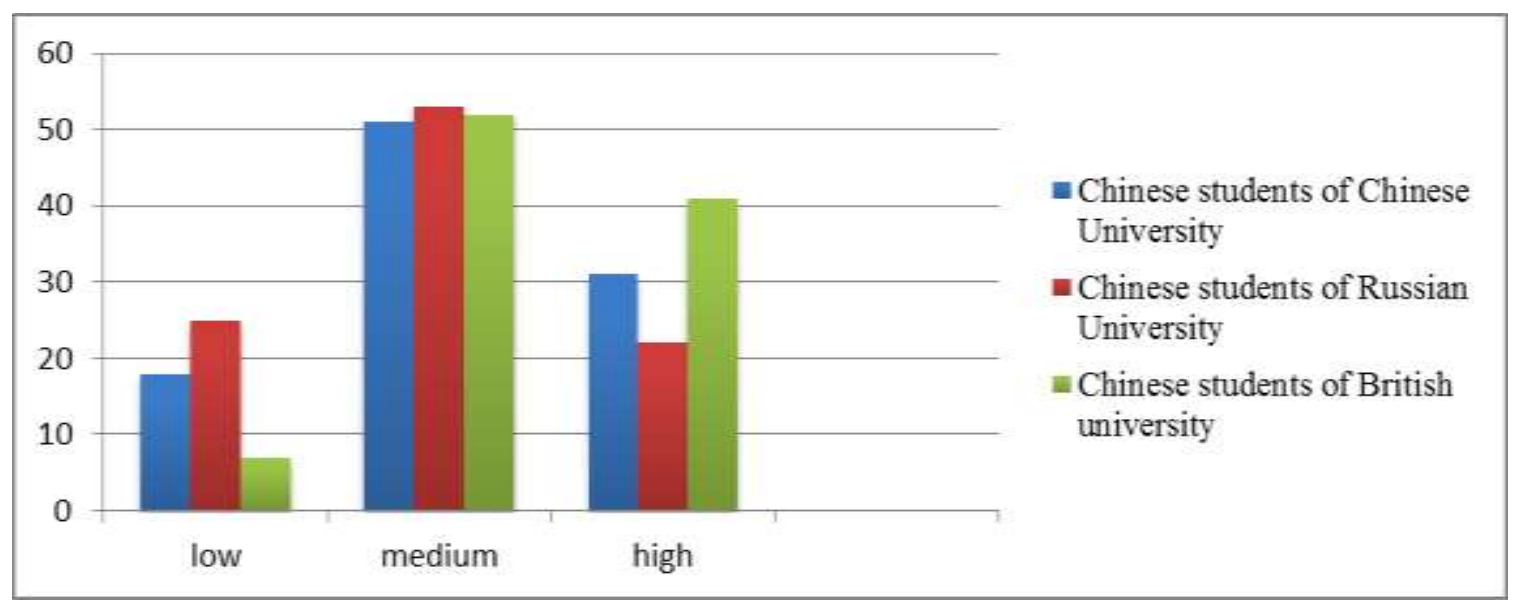

Figure 2. Percentages of Chinese students in the three universities within the three different levels of the motivational component of research potential.

In all three universities more than half of the respondents scored within the medium level of the motivational component of research potential. In the Chinese and British universities, the number of students who gained a high score for motivation for research was greater than those in the low category, and contrastingly in the Russian university students in the low category outnumbered those in the high category (Figure 2). 


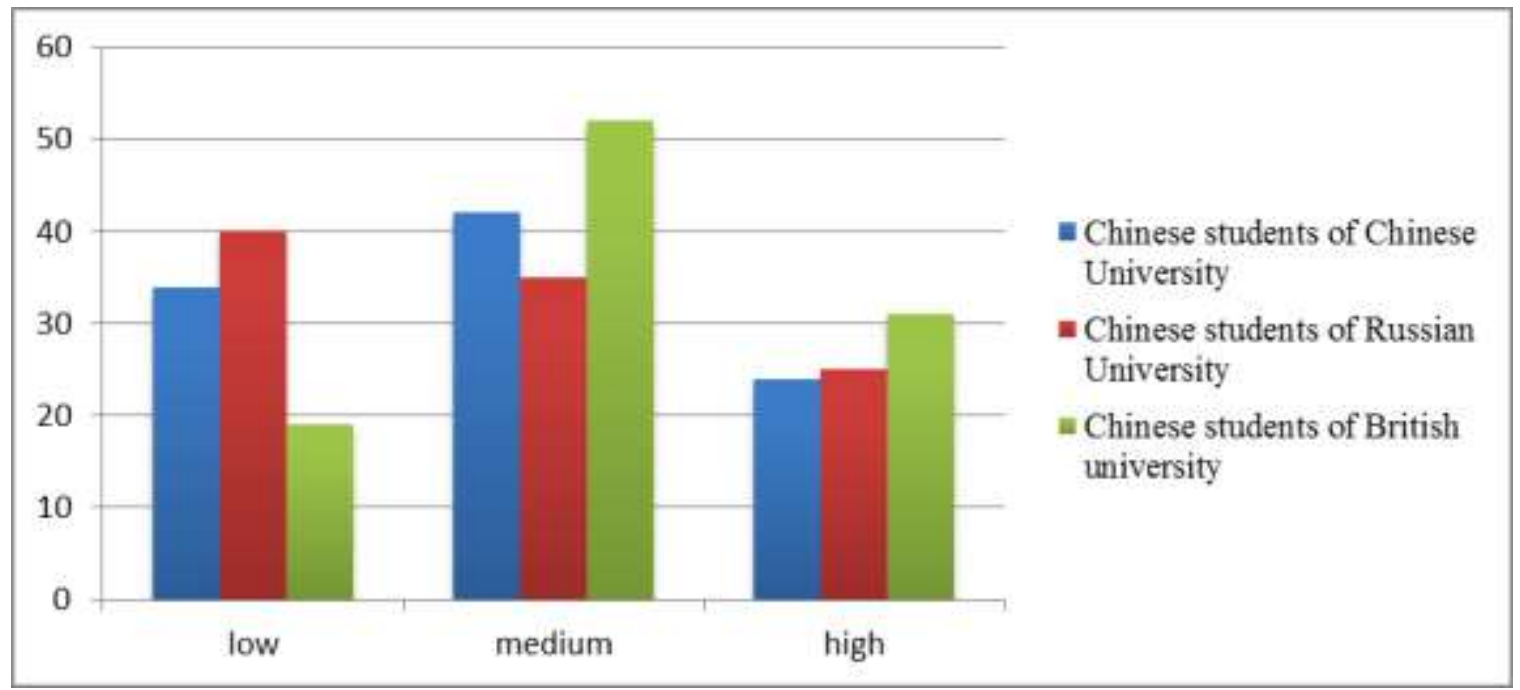

Figure 3. Percentages of Chinese students in the three universities within the three different levels of the cognitive component of research potential.

Figure 3 summarizes findings concerning the cognitive component of RP. The number of Chinese students within the medium level of the cognitive component of the RP (about $40 \%$ of students) is higher in the Chinese and British universities, while in the Russian university, Chinese students were more likely to have a low level of the cognitive component of the RP (40\%).

Less than $30 \%$ of respondents in the entire sample scored within the high category of the cognitive component of the RP (Figure 3).

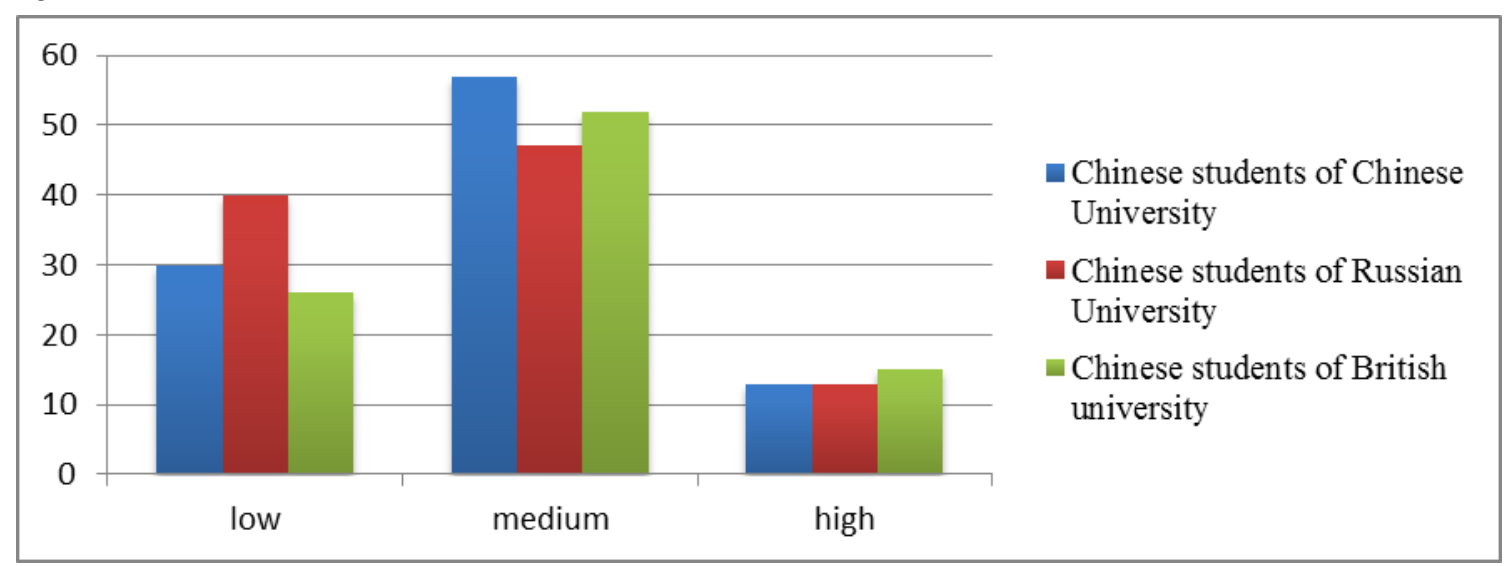

Figure 4. Percentages of Chinese students in the three universities within the three different levels of the behavioral component of research potential.

The scores on the behavioral component of the RP of many Chinese students in our study, regardless of the higher education institution, fall within the medium level while students with a high level of self-organization of research activities are significantly fewer than those with a low level (Figure 4).

\subsubsection{Comparison of the Indicator of the Research Potential (RP) and its Components}

Between Chinese first-year students studying at home and at the Russian university, significant differences were revealed only in the behavioral component of the RP; higher rates of the behavioral component of the research process were evident among students at the Chinese university $(\mathrm{p}<0.043)$.

The scores of students enrolled in the Chinese and British universities differed significantly in the total index of RP ( $p$ <0.025) and two of its components: "motivational" ( $p$ <0.006) and "cognitive" ( $p<0.023)$ - with the scores of Chinese students from the British university being higher than those of students studying at home. A possible explanation is that the students in the British university are at Masters level whereas the students in the Chinese and Russian universities are at Bachelor level. Comparison of the RP indicators of Chinese students studying at the British university and Russian university also revealed statistically significant differences: in the total indicator of the 
RP ( $p<0.003)$, its motivational component $(\mathrm{p}<0.000)$ and the cognitive component $(\mathrm{p}<0.018)$, with students at the British university scoring higher (Table 2).

Table 2. Statistically significant differences in indicators of RP of Chinese students studying in three countries.

\begin{tabular}{|c|c|c|c|c|}
\hline Parameters of RP & University of study & Mean & Mean Rank & $\begin{array}{l}\text { Significance } \\
\text { level }\end{array}$ \\
\hline \multirow[b]{2}{*}{ Total indicator of RP } & Russian University & 299.84 & 67.83 & \multirow[b]{2}{*}{0.003} \\
\hline & British University & 326.00 & 41.28 & \\
\hline \multirow{2}{*}{ Total indicator of RP } & Chinese University & 307.61 & 58.17 & \multirow{2}{*}{0.025} \\
\hline & British University & 326.00 & 75.63 & \\
\hline \multirow{2}{*}{$\begin{array}{l}\text { The motivational } \\
\text { component of RP }\end{array}$} & Chinese University & 91.72 & 57.31 & \multirow{2}{*}{0.006} \\
\hline & British University & 100.30 & 78.67 & \\
\hline \multirow{2}{*}{$\begin{array}{l}\text { The motivational } \\
\text { component of RP }\end{array}$} & Russian University & 88.41 & 71.03 & \multirow[t]{2}{*}{0.000} \\
\hline & British University & 100.30 & 29.91 & \\
\hline \multirow{2}{*}{$\begin{array}{l}\text { The behavioral } \\
\text { component of RP }\end{array}$} & Chinese University & 101.46 & 106.88 & \multirow{2}{*}{0.043} \\
\hline & Russian University & 97.74 & 90.46 & \\
\hline \multirow{2}{*}{$\begin{array}{l}\text { The cognitive } \\
\text { component of RP }\end{array}$} & Chinese University & 114.44 & 58.13 & \multirow{2}{*}{0.023} \\
\hline & British University & 123.52 & 75.78 & \\
\hline \multirow{2}{*}{$\begin{array}{l}\text { The cognitive } \\
\text { component of RP }\end{array}$} & Russian University & 60.00 & 67.79 & \multirow{2}{*}{0.018} \\
\hline & British University & 113.69 & 49.96 & \\
\hline
\end{tabular}

3.3 The Results of the Third Research Task: The Personal Characteristics of Chinese Students, Adapting to Study at Home and Abroad

In accordance with the norms introduced by the authors of the Big Five methodology, each of the five factors has three subgroups according to the level of the observed personality trait. The percentage of students with low, medium, and high levels of the Big Five personality traits is presented in Table 3.

Table 3. The percentage of students in each university in low, medium and high sub-groups of the Big Five personality traits for each factor

\begin{tabular}{lllll}
\hline Factors of Big Five & Factor levels & British University & Chinese University & Russian University \\
\hline \multirow{2}{*}{ Extraversion } & Low & 14.8 & 17.7 & 27 \\
& Medium & 51.9 & 38.5 & 34 \\
& High & 33.3 & 43.8 & 39 \\
\hline \multirow{2}{*}{ Agreeableness } & Low & 7.4 & 5.2 & 17 \\
& Medium & 40.7 & 12.5 & 20 \\
Conscientiousness & Low & 51.9 & $\mathbf{8 2 . 3}$ & $\mathbf{6 3}$ \\
(Self-control) & Hedium & 25.9 & 6.3 & 14 \\
\hline \multirow{5}{*}{ Neuroticism } & Low & $\mathbf{6 6 . 7}$ & 22.9 & 32 \\
\hline \multirow{5}{*}{ Openness } & Medium & 22.2 & $\mathbf{7 0 . 8}$ & 54 \\
\hline
\end{tabular}

The following general trends were identified for all three groups of Chinese students. These groups of Chinese students have the following personal resources: a positive attitude to others, self-regulation of behavior, and interest 
in various aspects of life. Traits appearing to impede effective adaptation to university study are neuroticism, and a low level of responsibility with a desire to evade problems. This means that at the first stage of university education, a sub-set of Chinese students, regardless of the socio-cultural learning environment, may experience psychological stress and apply non-productive coping.

Among the Chinese students enrolled at the British university, a large number have a high level of "self-control (conscientiousness)", which is combined with "openness" and "neuroticism". A large proportion of the Chinese students studying at the Russian university show a high level of "agreeableness" and "openness".

Among students studying at home, there are also many who have a high level of "agreeableness", as well as "openness" and "self-control (conscientiousness)." Thus, "openness" turns out to be a common personal quality for Chinese students in different sociocultural conditions.

"Agreeableness" as a personal quality is strongly expressed in a large number of Chinese students studying at the Russian university, but according to the findings presented in Table 3, there is reason to believe that this quality is less evident among Chinese students studying in Britain at a different level of education, i.e. at Masters level.

Table 4. Statistically significant differences in scores on factors of the Big Five of Chinese students, adapting to higher education at home and abroad.

\begin{tabular}{llccl}
\hline Factors of Big Five & University of study & Mean & Mean Rank & Significance level \\
\hline Conscientiousness & Chinese University & 101.46 & 108.65 & \multirow{2}{*}{0.014} \\
(self-control) & Russian University & 97.74 & 88.76 & \\
\cline { 2 - 4 } Agreeableness & Chinese University & 307.61 & 67.15 & \multirow{2}{*}{0.003} \\
& British University & 326.00 & 43.70 & \\
\hline
\end{tabular}

It can be seen from Table 4 that, according to the Mann-Whitney test, the factor "self-control (conscientiousness)" is expressed more strongly in students studying at home than in students at the Russian university $(\mathrm{p}<0.014)$.

The statistically significant differences between the students of the Chinese university and the British university found in the factor of "agreeableness" ( $p<0.003$ ) might possibly be interpreted as a result of the fact that in the British university environment Chinese students change their style of interaction with others, especially with teachers. No statistically significant differences were found in the factors of the Big Five between the students of the British university and the Russian university.

3.4 The Results of the Fourth Research Task: Relationships between Socio-Psychological Adaptation, Research Potential and the Personality Traits of Chinese Students Studying at Home and Abroad

To study the relationships between socio-psychological adaptation, research potential and personality traits Spearman's rho was used. Due to the fact that the highest rates of adaptation were found among Chinese students enrolled at the British university, we will begin by examining the relationships between these variables in this group of students.

Table 5. Correlations of the adaptability and personality traits of Chinese students studying at British university.

\begin{tabular}{lcc}
\hline Variable & $\begin{array}{l}\text { Adaptability of students studying at } \\
\text { British university } \\
\text { (correlation coefficients) }\end{array}$ & Sig. \\
\hline Research potential & 0.462 & $\mathbf{0 . 0 1 5}$ \\
The motivational component of RP & 0.361 & 0.064 \\
The cognitive component of RP & 0.350 & 0.074 \\
The behavioral component of RP & 0.537 & $\mathbf{0 . 0 0 4}$ \\
Extraversion & 0.536 & $\mathbf{0 . 0 0 5}$ \\
Agreeableness & 0.436 & $\mathbf{0 . 0 2 3}$ \\
Conscientiousness (Self-control) & 0.461 & $\mathbf{0 . 0 1 6}$ \\
Neuroticism & -0.597 & $\mathbf{0 . 0 0 1}$ \\
Openness & 0.326 & 0.097 \\
\hline
\end{tabular}


The correlation analysis (employing Spearman's rho) showed (Table 5) that the "adaptability" of Chinese students from the British university is positively related to their "research potential" $(\mathrm{p}<0.015)$, the "behavioral component of the RP" ( $p<0.004)$, "extraversion" ( $p<0.005$ ), "agreeableness" ( $p<0.023)$, "conscientiousness (self-control)" ( $p$ $<0.016$ ); and is negatively related to "neuroticism" ( $<<0.001$ ). This means that a sufficient level of readiness for research, (especially the ability to plan a research project and implement it), sociability, a positive attitude towards others and self-control are likely to contribute to the adaptation of Chinese students who begin their studies at a Master's program at the British university.

The data analysis identified "psychological targets" that should be taken into account when organizing various kinds of events to help Chinese students to improve their level of adaptation and optimize this process in the first months of study at the British university. Secondly, for Chinese first-year students who study at home self-monitoring and active participation in various types of research activities can contribute to overcoming adaptation difficulties at the beginning of their university education.

Table 6. Correlation between adaptability and personal characteristics of Chinese students studying at Chinese university

\begin{tabular}{lcc}
\hline Variable & $\begin{array}{c}\text { Correlation coefficient between } \\
\text { adaptability and the variable }\end{array}$ & $\begin{array}{c}\text { Significance } \\
\text { level }\end{array}$ \\
\hline Research potential & 0.321 & $\mathbf{0 . 0 0 1}$ \\
The motivational component of RP & 0.245 & $\mathbf{0 . 0 1 6}$ \\
The cognitive component of RP & 0.229 & $\mathbf{0 . 0 2 5}$ \\
The behavioral component of RP & 0.327 & $\mathbf{0 . 0 0 1}$ \\
Extraversion & 0.190 & 0.064 \\
Agreeableness & 0.112 & 0.236 \\
Conscientiousness (Self-control) & 0.232 & $\mathbf{0 . 0 2 3}$ \\
Neuroticism & -0.136 & 0.186 \\
Openness & 0.177 & 0.085 \\
\hline
\end{tabular}

Correlation analysis showed (see Table 6) that the "adaptability" of Chinese students at the home university is "positively" interconnected with: "research potential" ( $\mathrm{p}<0.001$ ), "behavioral component of RP" ( $\mathrm{p}<0.001$ ), "motivational component of RP" ( $p<0.016)$, "cognitive component of RP" ( $<<0.025)$, and "self-control" ( $p<0.023)$.

Table 7. Correlation between adaptability and personal characteristics of Chinese students studying at Russian university.

\begin{tabular}{lcc}
\hline Variable & $\begin{array}{c}\text { Correlation coefficient between } \\
\text { adaptability and the variable }\end{array}$ & Significance level \\
\hline Research potential & 0.271 & $\mathbf{0 . 0 0 6}$ \\
The motivational component of RP & 0.293 & $\mathbf{0 . 0 0 3}$ \\
The cognitive component of RP & 0.197 & $\mathbf{0 . 0 5 0}$ \\
The behavioral component of RP & 0.262 & $\mathbf{0 . 0 0 8}$ \\
Extraversion & 0.217 & $\mathbf{0 . 0 3 0}$ \\
Agreeableness & 0.226 & $\mathbf{0 . 0 2 4}$ \\
Conscientiousness (Self-control) & 0.247 & $\mathbf{0 . 0 1 3}$ \\
Neuroticism & -0.076 & 0.452 \\
Openness & 0.256 & $\mathbf{0 . 0 1 0}$ \\
\hline
\end{tabular}

The correlation analysis of the variables obtained by examining Chinese students studying at the Russian university showed (Table 7) that there are positive relationships between the adaptability of these students and their following personal characteristics: "RP" ( $\mathrm{p}<0.006)$, "the motivational component of RP "(p<0.003), "cognitive component of RP" (p <0.050), "behavioral component of RP" ( $<<0.008)$, "extraversion" ( $<<0.030)$, "agreeableness" ( $<0.024)$, "conscientiousness (self-control)" ( $\mathrm{p}<0.013)$ and "openness" ( $\mathrm{p}<0.010)$. 


\subsection{The Results of the Fifth Research Task: Personal Characteristics Associated with the Adaptability of Chinese Students Studying at Home and Abroad}

By means of multiple stepwise regression analysis, the following links between the social-psychological adaptability (SPA) of Chinese first-year students and their personal characteristics (as measured by the factors of the Big Five methodology) and parameters of Research Potential were identified.

\subsubsection{Predictors of the Socio-Psychological Adaptability of Chinese Students Studying at the British University}

For Chinese students at the British university, adaptability (SPA) is positively correlated with "extraversion" ( $\beta=$ $0.471, \mathrm{p}<0.001)$ and "conscientiousness (self-control)" $(\beta=0.272, \mathrm{p}<0.033)$, and negatively correlated with "neuroticism" $(\beta=-0.540, p<0.000)$. These findings suggest that "neuroticism" may impede some of these students' adaptation to the new learning environment of the British university.

The R squared of the linear model with adaptability as the dependent variable and these three independent variables is 0.689 (its adjusted value is 0.648 ) which suggests that the variability is explained reasonably well.

Thus, Chinese students with an external orientation of "conscientiousness (self-control)" and "emotional stability" are likely to be better adapted to the new socio-psychological educational environment of the British university. It is possible that Chinese students who possess these personal traits will have a wide circle of friends and participate in group events, contributing to better mastery of the English language - one of the chief challenges faced by Chinese students (Mashkina, 2010). It is known that extroverts are more likely than introverts to be optimistic about problems (Dong, 2010), and strong self-control is likely to assist them in adapting their behavior to new sociocultural norms. At the same time, Chinese students who find difficulty in controlling their emotions and have tendencies to act impulsively may cope less well with adapting to a new environment, and this can affect the level of their psychological stress in classes, and in interacting with teachers and other students.

Thus, to increase the level of socio-psychological adaptability of this group of Chinese students, it is advisable for educators of the British university to foster "emotional stability", "extraversion" and "conscientiousness (self-control)".

3.5.2 Predictors of the Socio-Psychological Adaptability of Chinese First-Year Students Studying in the Chinese University

The predictor of the adaptability of Chinese students studying in their homeland that emerged from the regression analysis is the level of development of their "research potential" $(\beta=0.279, p<0.003)$. That is, for Chinese students who study in their native language, the development of RP in the period of school education influences the success of their socio-psychological adaptation to the new conditions of higher education.

The R squared of the linear model with adaptability as the dependent variable and the independent variable "RP" is 0.239 (its adjusted value is 0.214 ). This is relatively low, so perhaps there are other factors not included in the model that would help to improve the model.

The findings of the regression analysis suggest that, in order to ensure that first-year students in Chinese universities adapt well to their new educational environment, it is important to create conditions for the development of their "research potential" and "conscientiousness (self-control)" at school before entering university, or to encourage them to develop these personal qualities from the first days of study at a university.

3.5.3 Predictors of the Socio-Psychological Adaptability of Chinese First-Year Students Studying in the Russian University

The regression analysis revealed the positive relationship between the adaptability of Chinese first-year students studying at the Russian university and the level of their "research potential" ( $\beta=0.296, p<0.003)$. This finding needs to be viewed against the ethos of higher education in Russia and the status of the Russian university where the study took place as a research university where the priority of education is the active application of research methods and the inclusion of students from the first year of study in the discussion of scholarly problems and work in scientific laboratories.

The R squared of the linear model with adaptability as the dependent variable and the independent variable, research potential, is 0.088 (its adjusted value is 0.079 ). This is very low, so perhaps there are other factors not included in the model that would help to improve the fit.

The regression analysis shows that the adaptability of Chinese undergraduates studying at home and at the Russian university is associated with the development of their research potential. This fact is important in the preparation of 
school leavers to continue their studies in universities in their homeland and universities in Russia.

\section{Discussion}

\subsection{Summary of Key Findings of the Study}

1. The study has established that the socio-psychological adaptation of Chinese first-year students studying at home and abroad falls within the medium and high levels. The adaptability of Chinese undergraduate students in the British university is higher than that of Chinese undergraduate students at the Russian university and studying at home. Chinese first-year students at the British university differ from other respondents by higher indicators of the adaptive individual qualities of: "self-acceptance," "accepting others" and "emotional comfort", and by a lower indicator of "dependence".

2. Around $40 \%$ of the Chinese students at the three universities scored within the medium level of RP. About one third of students studying at the Russian and Chinese universities scored within the low level of RP, and one third of students from the British university within the high level of RP. It is noteworthy that the scores of the structural components of the RP of Chinese students are higher in the educational environment of a foreign university (mostly in the British university): these students have more developed motivation for research, and greater understanding of the cognitive demands of university study than Chinese students studying in their homeland. In general, Chinese students enrolled at the British university have higher scores on all components of RP.

3. The study has identified personal qualities characteristic of all the Chinese respondents: a positive attitude towards others, self-control of behavior, and interest in various aspects of life. These qualities can contribute to their adaptation to new learning conditions. However, other qualities displayed by some of these Chinese students have been identified that can hamper effective adaptation to higher education, especially abroad: a high level of emotional instability, not having a high level of personal responsibility along with the desire to evade reality.

Chinese students studying at the British university have higher scores on "conscientiousness (self-control)". Among students studying in their homeland and in the Russian university, there are more who have a high level of "agreeableness" than those at the British university.

4. The interrelations between the psychological qualities of Chinese students have been set out in earlier sections of this article establishing that: sociability, a positive attitude toward others, self-control in behavior and a sufficient level of RP contribute to the adaptation of all Chinese students, regardless of the country of study. For Chinese undergraduate students at the British university, this relationship is strongest.

\subsection{Conclusions}

Pursuing its central research questions, this study has identifed personal predictors of the socio-psychological adaptability of Chinese students studying at home and abroad, identifying similarities and differences between the three groups of respondents.

For all Chinese students, the common predictors of adaptation to university education are "openness" and "agreeableness". Personal resources for adaptation of the Chinese students in the Chinese and Russian universities are similar and are related to "research potential". This differs from the personal resources for adaptation in the British university which are "emotional stability", "extraversion" and "conscientiousness (self-control)".

The practical significance of this study is that the obtained new knowledge can underpin the development of specialized programs of psychological and pedagogical assistance and support of Chinese first-year students, necessary at the stage of their adaptation to university education. Such programs should enhance:

- the "conscientiousness (self-control)" of each student in overcoming the problems of psychological adjustment and social communication, in students at home and in the British university;

- the level of development of the "research potential" for students in the Chinese university and the Russian university.

\section{Acknowledgements}

Nina Bordovskaia is grateful to St.Petersburg State University, Russia, for travel support to visit The University of Edinburgh, UK for the purpose of this work. 


\section{References}

Allport, G.W. (1955). Becoming: Basic Considerations for a Psychology of Personality. New Haven: Yale University Press.

Berry, J. W. (2005). Acculturation: Living successfully in two cultures. International Journal of Intercultural Relations, 29, 697-712. https://doi.org/10.1177/1475240908091306

Bezyulyova, G.V. (2008). Complex psychological and pedagogical support of professional self-representation of students of colleges and universities. Proceedings of the Academy of Pedagogical and Social Sciences-Part II, 102-109. Moscow. (in Russian)

Biggs, J.B. and Watkins, D.A. (2001). The paradox of the Chinese learner and beyond. In D.A. Watkins and J.B. Biggs (Eds.), Teaching the Chinese Learner: Psychological and Pedagogical Perspectives (pp. 3-23). Hong Kong: CERC.

Bordovskaia, N. (2013). Research potential of students and special features of its realization in the learning process. International Journal of Pedagogy and Curriculum, 19(3), 165-176. https://doi.org/10.18848/2327-7963/CGP/v19i03/48857

Bordovskaia, N.V., Fan, Q. (2016). Studying the adaptation of Chinese first-year students to study at a Russian university and their research potential. Ananiev readings "Psychology - Yesterday, Today, Tomorrow." Abstracts of the international scientific conference. 25-29 October. St. Petersburg: St. Petersburg State University. (in Russian)

Bordovskaia, N.V., Kostromina, S.N., Rozum, S.I., Moskvicheva, N.L. (2017). Student's research potential: the content of the construct and the methodology for its evaluation. Psihologiheskyi Jurnal, 38 (1), 52-66. (in Russian)

Brown, L. \& Holloway, I. (2008). The adjustment journey of international postgraduate students at an English university: an ethnographic study. Journal of Research in International Education, 7(2), 232-249. https://doi.org/10.1177/1475240908091306

Currie, G. (2007). 'Beyond Our Imagination': The Voice of International Students on the MBA. Management Learning, 38(5), 539-556. https://doi.org/10.1177/1350507607083206

Danilenko, O.I., Li, Ts., Xu, I. (2015). Adaptability of Chinese students at different stages of education in universities of Russia and China. In V.V. Kalita (Ed.), Psychological aspects of intercultural adaptation (pp. 90-110). Vladivostok. (in Russian)

Dong, Z. (2010). Students' self-concept with school adjustment. Journal of Chuzhou university, 12(6), 238-240.

Edwards, V., Ran, A. \& Li, D. (2007). Uneven playing field or falling standards?: Chinese students' competence in English. Race Ethnicity and Education, 10(4), 387-400. https://doi.org/10.1080/13613320701658431

Fan, Q., Petanova E. (2017). The problem of activating the research activity of students in the work of Chinese psychologists. Pedagogy \& Psychology. Theory and practice, 6(14), 67-70. (in Russian)

Gao, X. (2005). A tale of two mainland Chinese learners. The Asian EFL Journal Quarterly, 7(2), 4-23.

Gu, Q. (2011). An Emotional Journey of Change: The Case of Chinese Students in UK Higher Education. In L. Jin and M. Cortazzi (Eds.). Researching Chinese Learners: Skills, Perceptions and Intercultural Adaptations (pp.212-232). Basingstoke: Palgrave Macmillan. https://doi.org/10.1057/9780230299481_10

$\mathrm{Gu}, \mathrm{Q}$. and Schweisfurth, M. (2006). Who adapts? Beyond cultural models of 'the' Chinese learner. Language, Culture and Curriculum, 19(1), 74-89. https://doi.org/10.1080/07908310608668755

Gu, Q., Schweisfurth, M. \& Day, C. (2010). Learning and growing in a 'foreign' context: intercultural experiences of international students. Compare: A Journal of Comparative and International Education, 40(1), 7-23. https://doi.org/10.1080/03057920903115983

Jimenez, M.I., Lopez-Zafra, E. (2011). Social attitudes and social adaptation among Spanish adolescents: The role of perceived emotional intelligence. Revista de psicologia social, 26(1), 105-117. (in Spanish) https://doi.org/10.1174/021347411794078417

Jin, L. \& Cortazzi, M. (2006). Changing Practices in Chinese Cultures of Learning. Language, Culture and Curriculum, 19(1), 5-20. https://doi.org/10.1080/07908310608668751 
Kember, D. (1996). The intention to both memorize and understand: another approach to learning? Higher Education, 31(3), 341-354. https://doi.org/10.1007/BF00128436

Kong, W. (1991). Types of adaptation and the ability to adapt. Huaibei Normal University Journal, 3, 65-69.

Kostromina, S.N., Bordovskaia, N.V., Rosum, S.I., Moskvicheva, N.L., Iskra, N.N. (2014) Research potential and cognitive features of students. Psychology in Russia: State of the Art, 7(4), 122-136. https://doi.org/10.11621/pir.2014.0411

Liang, B. (2004). The thinking on the quality and the structure of the psychological health. Tianjin: Psychological and behavioral research, 2(4), 577-581.

Liu, J., Petanova, E.I. (2016). Interrelationships between the adaptability and cognitive-behavioral personality features (on the example of Russian and Chinese first-year students). Journal of the St. Petersburg State University. Series-16, 4, 59-66. (in Russian)

Marton, F., Dall'Alba, G. \& Kun, T.L. (1996). Memorising and understanding: the keys to the paradox? In D. Watkins and J.B. Biggs, (Eds.), The Chinese Learner: Cultural, Psychological and Contextual Influences (pp. 69-84). Hong Kong and Melbourne: CERC and ACER.

Mashkina, O.A. (2010). Chinese students and undergraduates in Russian universities: the problems of social, cultural and linguistic adaptation. Civilization of knowledge: the problems of Russia's modernization: Proceedings of the Eleventh International Scientific Conference. Moscow, 208-215. (in Russian).

Pak, I.Ya., Wang, D. (2008). Cultural shock of Chinese students studying in Russian universities, ways to overcome it. In Methodology of teaching and improving the effectiveness of academic, socio-cultural and psychological adaptation of foreign students in a Russian university: theoretical and applied aspects: materials of the Russian National Seminar, 2, 91-96, Tomsk: Izdatel'stvo TPU (in Russian).

Petanova E., Bordovskaia N., Fan Q., Wang X. (2017). Predictors of the actualization of the research potential of Chinese first-year students studying at home and in Russian universities. EDULEARN 17 Proceedings, 7518-7522. https://doi.org/10.21125/edulearn.2017.0346

Rogers, C.R., \& Dymond, R.F. (Eds.) (1954). Psychotherapy and personality change: Coordinated research studies in the client-centered approach. Chicago: University of Chicago Press.

Shamionov R. M., Grigoryeva M. V., Grigoryev A. V. (2014). Influence of beliefs and motivation on social-psychological adaptation among university students. Procedia-Social and Behavioral Sciences, 112, 323-332. https://doi.org/10.1016/j.sbspro.2014.01.1171

Spencer-Oatey, H., Dauber, D., Jing, J., Lifei, W. (2017). Chinese students' social integration into the university community: hearing the students' voices. Higher Education, 74, 739-756. https://doi.org/10.1007/s10734-016-0074-3

Tian, M. and Lowe, J. (2012). The role of feedback in cross-cultural learning: a case study of Chinese taught postgraduate students in a UK university. Assessment and Evaluation in Higher Education, 38(5), 580-598. https://doi.org/10.1080/02602938.2012.670196

Xu F., Yu P., Li M. (2005). The Relationship Between College Students' Learning Adaptability and Their Personality Characteristics and Social Support. Chinese Journal Of School Health, 26(4), 299-300.

Ward, C. (1996). Acculturation. In D. Landis and R. Bhagat (Eds.), Handbook of intercultural training, 2nd. Edn. (pp. 124-147). Newbury Park: Sage.

Ward, C., Bochner, S., \& Furnham, A. (2001). The Psychology of Culture Shock. (2 ${ }^{\text {nd }}$. Edn.) Hove: Routledge.

Zhao, T., \& Bourne, J. (2011). Intercultural adaptation - it is a two-way process: examples from a British MBA programme. In L. Jin and M. Cortazzi (Eds.), Researching Chinese Learners: Skills, Perceptions and Intercultural Adaptations (pp. 250-273). Basingstoke: Palgrave Macmillan. https://doi.org/10.1057/9780230299481_12

Zhao, W., Sangster, P., Hounsell, D. (2017). Chinese first-degree students' transitions to postgraduate studies in the UK. In E. Kyndt, V. Donche, K. Trigwell, S. Lindblom-Ylänne (Eds.), Higher Education. Transitions. Theory and Research (pp. 189-207). Abingdon: Routledge. 